\title{
Corporate treatment for the ills of academic medicine
}

\section{Citation}

Garber, Alan M. 2004. Corporate treatment for the ills of academic medicine. New England Journal of Medicine 351, 16:1601-1603.

\section{Published Version}

doi:10.1056/NEJMp048215;http://www.nejm.org/doi/full/10.1056/NEJMp048215

\section{Permanent link}

http://nrs.harvard.edu/urn-3:HUL.InstRepos:11595733

\section{Terms of Use}

This article was downloaded from Harvard University's DASH repository, and is made available under the terms and conditions applicable to Other Posted Material, as set forth at http:// nrs.harvard.edu/urn-3:HUL.InstRepos:dash.current.terms-of-use\#LAA

\section{Share Your Story}

The Harvard community has made this article openly available.

Please share how this access benefits you. Submit a story.

Accessibility 
best treated by a combination of psychotherapy and medication.

The FDA's recent analysis suggests that the risk of emergent suicidality in children and adolescents receiving SSRIs is real - but small. The FDA's advisors recommended stronger warnings in labeling and better information for patients and caregivers, but they stopped short of recommending contraindications for these drugs. However, many participants in the public hearing seemed convinced that the pharmacologic treatment of pediatric depression should be banned or severely curtailed. That would turn the clock back 25 years, to a time when the only thing we could offer the families of suicide victims was the hope that someday we would have effective treatments. Ideally, the FDA, families, and clinicians will find the right balance between the risk of suicidality and another, greater risk: the risk that lies in doing nothing.

From the Western Psychiatric Institute and Clinic, Department of Psychiatry, University of Pittsburgh Medical Center, Pittsburgh.

1. Brent DA, Perper JA, Goldstein CE, et al. Risk factors for adolescent suicide: a comparison of adolescent suicide victims with suicidal inpatients. Arch Gen Psychiatry 1988;45:581-8.

2. March JS, Silva S, Petrycki S, et al. Fluoxetine, cognitivebehavioral therapy, and their combination for adolescents with depression: Treatment for Adolescents With Depression Study (TADS) randomized controlled trial. JAMA 2004;292:807-20.

3. Webster DW, Vernick JS, Zeoli AM, Manganello JA. Association between youth-focused firearm laws and youth suicides. JAMA 2004;292:594-601. [Erratum, JAMA 2004;292:1178.]

4. Olfson M, Shaffer D, Marcus SC, Greenberg T. Relationship between antidepressant medication treatment and suicide in adolescents. Arch Gen Psychiatry 2003;60:978-82.

5. Martin A, Young C, Leckman JF, Mukonoweshuro C, Rosenheck R, Leslie D. Age effects on antidepressant-induced manic conversion. Arch Pediatr Adolesc Med 2004;158:773-80.

BUSINESS AND MEDICINE

\title{
Corporate Treatment for the Ills of Academic Medicine
}

\author{
Alan M. Garber, M.D., Ph.D.
}

These are anxious times for academic medical centers, which have reacted to recent developments with measures that were beyond contemplation in a more optimistic past. Confronted by the challenges of managed care, decreases in reimbursement, restrictions on house-staff working hours, heightened scrutiny of clinical research, declining federal support for medical education, and the growth of formidable competitors such as hospital chains and medical practices specializing in high-margin services, academic medical centers can no longer be complacent about their financial health or their reputations as the best places to receive care. Many of these institutions have political clout and access to considerable private wealth, but none can count on a bailout from government or donors if they founder. Nearly all have adopted tighter management practices and worked to eliminate inefficiencies. Many have reorganized, and some, like Stanford University Medical Center and the University of California at San Francisco, and Brigham and Women's Hospital and Massachusetts General Hospital, have merged with erstwhile rivals. As these institutions attempt to run themselves like other large enterprises, their faculty, affiliated physicians, and many others question whether a preoccupation with costs and revenues will distract them from their traditional missions.

Anyone who believes that academic centers have lost their way by adopting corporate practices must surely have been alarmed by the news of a "partnership" between GE Medical Systems and New York-Presbyterian Hospital, the organization that resulted from the merger of the hospitals of Cornell University and Columbia University. Under the terms of this partnership, New York-Presbyterian will spend a reported $\$ 500$ million, over 10 years, on products and services from GE, ranging from imaging equipment to change-management programs to training in process-improvement and quality-improvement programs. The agreement tied together a broadly diversified medical products and services business, with revenues of approximately $\$ 9$ billion at the time, with one of the dominant health care providers in New York City, a 2400-bed hospital system with $\$ 2$ billion in annual revenue.

Academic medical centers routinely spend millions of dollars on equipment from GE and its competitors, and they engage consultants for everything from operational assistance to informa- 


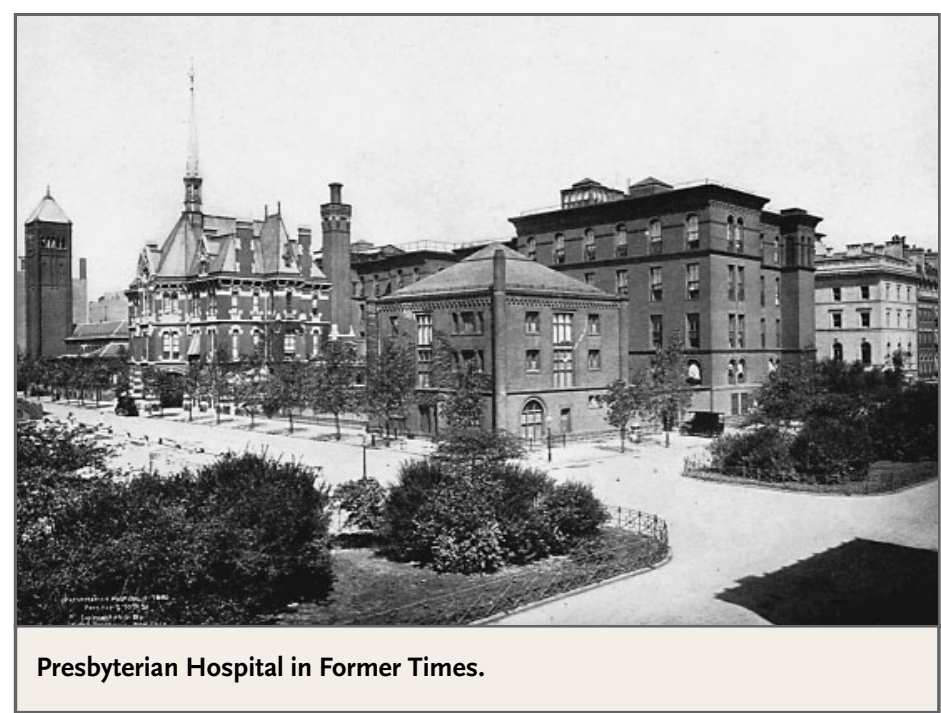

tion technology support to strategy. Nevertheless, the magnitude and scope of this agreement make it stand out. And inevitably, a series of questions have followed: Will this agreement really benefit the hospital? Are aspects of the agreement likely to impair competition among providers, or among suppliers? Most important, is this transaction in the best interests of patients and the public, as both parties have claimed? Or will the quest for financial success inevitably conflict with the hospital's responsibilities to the public?

Ultimately, only people who know the hospital's needs well and have seen the details of the agreement can judge whether it was in the hospital's interest at the time it was negotiated. But even if it seemed attractive then, things might look different in hindsight. That is a risk with any long-term agreement. The hospital's forecasts of future demands for GE imaging technology and reengineering and management services could be far off the mark. Both partners could be overly optimistic about the operating savings that the consulting services will provide - according to a press release from GE, $\$ 100$ million over five years. But every business must make bets about the future, and skillful managers rely on astute analysis of the best available information. Presumably the management and the board of the hospital - which includes some of the most prominent names in American business - scrutinized the agreement thoroughly before making a commitment of this magnitude. It would be surprising if New York-Presbyterian failed to secure highly favorable terms.

If, as GE undoubtedly expects, the discounts and other aspects of its agreement with the hospital freeze out competitors such as Siemens, the hospital will be effectively tied to a single vendor for many of its purchases. This "lock-in" has significant potential disadvantages, especially if in a few years GE's offerings turn out to be much less attractive than those of its competitors. But there can be important advantages as well. Reducing the number of vendors means that the hospital will purchase fewer versions of similar products. Nurses in some hospitals use five or six different types of intravenous infusion pumps that operate in slightly different ways. These pumps are only one of the many kinds of equipment that they routinely operate, and the complexity of their tasks multiplies with each minor variation in a piece of equipment. As the Institute of Medicine has noted, standardization and simplification can prevent errors. It can also simplify staff training and lower ongoing service costs. Similar simplification of vendor relationships and the integration of services and equipment appeal greatly to hospital management.

Another potential problem is that GE Medical, in its consulting role, could make recommendations that are not in the hospital's best interest. A hospital might want to draw on GE's expertise in deciding whether to replace a magnetic resonance scanner with a newer, higher-resolution model. Can GE Medical give disinterested advice about the purchase of a product or service that it sells? The potential for such a conflict is great when a vendor offers as broad a range of products and services as GE Medical does.

Conflicts of this kind are widespread. The business world wrote off IBM as a corporate dinosaur before it shifted its focus to profitable consulting services, which became a vehicle for selling IBM hardware and software. Many financial planners dispense advice for minimal or no fees, earning revenues from commissions on mutual funds that they recommend. Financial conflicts are no less common in medicine. Physicians routinely give patients advice about procedures that the doctors are paid to perform, while nearly the opposite concern arises in some managed-care settings, where physicians have financial incentives to withhold care. In such instances, conflict can be limited by the so- 
phistication of the clients and the value the seller or agent places on future business and reputation. The drawbacks of obtaining guidance and services from advisers whose interests diverge from those of the client are unfortunate but generally accepted, as long as there is full disclosure of the potential conflicts. Any such conflicts in GE's role should be known to the hospital, and GE surely recognizes that the success of its relationship with New YorkPresbyterian and its ability to form other similar relationships depend on the hospital's continuing satisfaction with the arrangement.

If GE's quality- and process-improvement programs enable a hospital to make better use of its operating rooms, eliminate unnecessary duplication of tests, and shorten waiting times in clinics, the hospital and its patients benefit. But any consultant could also help a hospital's financial performance by pursuing strategies that do not benefit the public. Many academic hospitals could improve their bottom lines by cutting the amount of uncompensated care they provide and eliminating unprofitable services. They might also promote excessive use of high-margin services. For example, to the extent that physicians induce demand, any hospital that owns a scanner - and any physician who earns fees by interpreting scans - can raise revenues by performing scans for less critical or even dubious indications. Similarly, well-reported phenomena such as "DRG creep," "upcoding," and "unbundling" can increase health care expenditures without benefiting patients. Such practices may seem innocuous from the individual patient's point of view, if they merely raise health expenditures generally. But a physician or hospital that takes advantage of reimbursement anomalies can also jeopardize patients' health. Physicians and hospitals can be reimbursed more if a candidate for the placement of multiple coronary stents has the procedure divided among two or more hospital admissions than if they are placed as part of a single complex procedure. Is it plausible that clinical needs alone explain why so many patients have stents placed as part of multiple admissions?

No institution with a reputation to preserve whether for-profit or nonprofit, medical center or consulting firm - can risk encouraging or engaging in any practice that might be construed as fraudulent or unethical. Nevertheless, one cannot presume that what is good for the hospital and the consultant is good for society. Does this imply that a successful partnership between GE Medical Systems and New York-Presbyterian Hospital will not serve the public interest and that such arrangements should be discouraged? I believe that would be the wrong conclusion. The problem is not that GE Medical and its competitors are seeking to make hospitals more efficient. The problem is that hospitals are not always rewarded for providing care that is both of the highest quality and appropriate. The task of GE Medical is to help the hospital respond to the incentives it faces. The responsibility of those of us who are concerned about the future of health care is to make sure that the incentives they face are the right ones. It is a responsibility that we cannot delegate.

From the Department of Veterans Affairs Palo Alto Health Care System, Palo Alto, Calif., and Stanford University, Stanford, Calif.

\section{Cardiopulmonary Bypass after 50 Years}

L. Henry Edmunds, M.D.

A little more than 50 years ago, a hole inside a human heart was closed, with a machine maintaining life while the surgery was done. Within the next two years, four of eight children survived repair of complicated congenital heart defects in operations involving a similar machine. The heart-lung machine, as it was called, was invented and devel- oped by John and Mary Gibbon (see Figure 1). Simultaneously, Forssmann, Cournand, and Richards developed cardiac catheterization that permitted anatomical and physiological diagnoses of heart disease during life. With the discovery and commercial production of the anticoagulant heparin, these two innovations spawned the modern surgical 